\title{
AN INVESTIGATION OF MORPHOLOGICAL PRODUCTIVITY OF NOMINAL AND VERBAL COMPOUNDS IN LEGAL DISCOURSE
}

\author{
Jeta Hamzai \\ South East European University, Tetovo, North Macedonia \\ jeta.rushidi@seeu.edu.mk
}

\begin{abstract}
Compounding is one of the most productive word-formation processes in contemporary Standard English. Hence, new patterns occur regularly. Productivity is one of the characteristic features of human language which implies the ability to create and understand new word forms by the speaker of a language. This was the starting point and motivation of this paper. The main aim of this paper was to investigate the morphological productivity of nominal and verb compounds in English as a foreign language in terms of the most productive and the least productive patterns of compounds in a written English corpus (consisted of 60073 words) by 75 students enrolled in undergraduate studies at the Law Faculty at SEEU. The quantitative measure used for the evaluation of the productivity of compounding patterns was according to hapax legomenon $\left[\mathrm{P}=\mathrm{n}_{1} / \mathrm{N}\right]$. Findings from the empirical approach show that the most productive compounds in the analyzed corpus (professional/Legal English context) are verb compounds, followed by special noun compounds, whereas the least productive were noun compounds. The analysis of the corpus showed that morphological productivity in compounding increased in the writing of students with higher degree of competence and proficiency of English.
\end{abstract}

Key words: compounds, morphological productivity, English language, legal English, corpus. 


\section{INTRODUCTION}

Language is dynamic and is constantly changing. One of the distinguishing features of the human language is productivity. It implies the ability to create and understand new forms of language of the speaker. This paper presents one of the most common word formation processes in English, through which new words are formed regularly. The more new words are used, the more they are more productive. The more new word-formation processes are applied in one language, the more productive that language is. The paper refers to one of the aspects of compounding, namely the issue of productivity, which is very important in this process. In addition, a quantitative analysis of morphological productivity was conducted in the writing of EFL students.

In recent centuries many compound words have appeared in the language community (Finnegan 2007: 321). In this paper the term compounding refers to the process in which two or more lexemes are combined into a new word. When a word is formed by joining two or more words, each of which can be used separately, it is called a compound word. Word formation is sometimes defined as a process associated with changing the form of the word, for example, the affixation, which, in fact, is the subject of morphology. In a wider sense, word formation involves the processes of creating new lexical units. In English, word-formation is of great importance because this phenomenon affects the English-language dictionary, which, besides the borrowings from various other languages, is enriched in this way.

\section{PREVIOUS STUDIES}

The latest research on derivational morphology has exposed a novel significance in the theory of morphological productivity and its various measuring instruments: quantitative (Baayen 1992, Baayen \& Lieber, 1991; Baayen \& Renouf, 1996) and qualitative (Bauer, 2001). However, the morphological productivity of compound words has been very little researched, especially in Macedonia.

Fernández-Domínguez (2013) argues that morphological productivity was originally described as the characterization of word-forming processes, with new words being created to satisfy the need for naming. The definition is later backed up by the classical division of availability and profitability from (Corbin in 1987). Despite the importance of these two concepts, they are traditionally neglected in the design and discussion of productivity calculations. Corbin examines eight approaches to measuring productivity in his paper and confirms that even if all 
these models can assess productivity, their methodology refers to both: availability or profitability. In particular, most of the methods examined focus on quantitative productivity, with only two suggestions: onomasiological approach and hybrid approach, showing qualitative properties - a situation that appears to originate from the theoretical attitude of each model. Nevertheless, despite certain attitudes, it is clarified that within most models only attention is paid to one of the aspect sides of productivity, showing a partial view of this phenomenon and neglecting the complex nature of word formation.

Noun compounds are noticed in Mesoamerican languages (Campbell, Kaufman, and SmithStark, 1986) and in other languages (Mixean) (Romero-Méndez, 2008, and Van Haitsma, 1976), but there are no studies investigating their formal properties or their productivity, which is probably due to the fact that noun compounds are an area that has not been studied very much in polysynthetic languages where most of the information is covered by the verbs.

Another researcher, Sabri Faris (2003), in his paper "Analysis of word formation - the productivity of compounding in English short stories", claims that based on the data obtained from the analysis, not all types of word formation are used in the stories. For example, in the analyzed short story, 167 new words are formed from older words. There are three types of word-formation processes used in their formation. They are affixation, compounding and conversion.

In the analyzed story, affixation or derivation is the most common form of word formation because it has the largest share in the formation of 113 new words. The second most common form of word formation is compounding. There are compounds in the story, and 13 new words are created through conversion. Still, these results show the high productivity of these threeword formation processes in English.

\section{PRESENT STUDY}

\section{Research Questions}

This paper aimed to analyze the morphological productivity of noun compounds, special noun compounds and verb compounds in English as a foreign language where through the following research questions: 
1) Which compounds (noun compounds, special noun compounds, or verb compounds) are most productive in Legal English written discourse?

2) Which compounds (noun compounds, special noun compounds, or verb compounds) are least productive in in Legal English written discourse?

\section{Instruments}

The instruments used in this paper were research papers written by EFL students who attended the following courses: Academic English, Advanced Academic English, English for specific purposes 1 and 2 (ESP Law $1 \&$ 2). The analyzed corpus consisted of 60073 words (363 pages) or seventy-five research papers related to legal studies provided through Google Classroom where students submitted their written assignments. Students conducted research on topics such as: civil law, criminal law, criminal procedure rules, proceedings with a claim, court structure and jurisdiction, court process, family law, separation and divorce, child custody, freedom of speech and expression, EU institutions, etc. Students were guided through all the semester while conducting their research through in-class conferencing. They submitted their final draft at the end of the semester.

Subsequently, this written corpus was analyzed by identifying the compounds manually since it is impossible to detect thirteen patterns of compounds through any software. This would be possible if the researcher was looking at specific compounds ending with specific heads. In this case the researcher came up with a list of the identified compounds which consisted of 3574 words (the list is available upon request). Through this corpus, a quantitative analysis of the morphological productivity of compounds was done. The quantitative measure used to evaluate the productivity of the compounding patterns was hapax legomenon (Baayen \& Lieber, 1991; Baayen, 1992). Productivity is determined by the formula $[\mathrm{P}=\mathrm{n} 1 / \mathrm{N}]$ where $\mathrm{P}$ represents the productivity in the narrow sense (the growth rate of the vocabulary), n1 represents the number of the hapax legomonone (of forms that appear only once in a large corpus), and $\mathrm{N}$ represents the total number of observed events in the corpus where the derivational type is analyzed. This measure was used in order to detect the most productive and not the most frequent compounds students use. 


\section{Participants}

The participants involved in this study were 75 students studying at South East European University in Tetovo and Skopje, Macedonia. These 75 Law students were from the first, second and third year attending the following courses: Academic English, Advanced Academic English, English for Specific Purposes 1\& 2 (ESP Law $1 \& 2$ ).

\section{FINDINGS AND DISCUSSION ON THE FINDINGS}

The morphological productivity of compounds was determined by the formula $[\mathrm{P}=\mathrm{n} 1 / \mathrm{N}]$ where $\mathrm{P}$ represents the productivity in the narrow sense (the growth rate of the vocabulary), $\mathrm{n} 1$ represents the number of words of the type hapax legomenon (on forms that appear only once in a large corpus), and $\mathrm{N}$ represents the total number of observed phenomena in the corpus where the derivational type is analyzed. According to this measure of productivity, the category of high frequency words has a great value of $\mathrm{N}$ and, accordingly, a low degree of productivity. So the more words of the hapax type exist in a given corpus the higher is the productivity rate. The higher the number of high-frequency words in the corpus, the lower the productivity is (Plag, 2003: 57). Thus, productivity "is characterized by a number of low-frequency words" (Plag, 2004: 9). A number of words of the type of hapax lead to a high value of $\mathrm{P}$ indicating a productive morphological process. In contrast, many high frequency words / forms lead to a high $\mathrm{N}$ value, hence a reduction in $\mathrm{P}$, indicating low productivity.

The procedure involved in the analysis of the morphological productivity of compounds in the written discourse went through several stages. First, the corpus consisted of 60073 words was analyzed and identified 3574 noun, verb, adjective, adverb, and special noun compounds (consisted of two roots only and formed according to the thirteen patterns of compounding). Subsequently, all identified compounds were analyzed in terms of the morphological productivity.

\section{THE IDENTIFIED NUMBER OF COMPOUNDS IN THE CORPUS (THE WRITTEN DISCOURSE)}

The morphological classification of compounds in the analyzed corpus was performed on the basis of thirteen patterns of compounding. Findings show that $5.94 \%$ or $6 \%$ of the analyzed written discourse (consisted of 60073 words) consists of compounds formed by two roots, while the remaining $94 \%$ of the words are formed by other word formation processes. The 
identified compounds are not very numerous since only compounds made up of two roots and which are formed by thirteen models of compounding are the object of this paper. In these types of compounds, one root can be for example a noun, and the other can be another noun, verb, adjective, or adverb. Based on the analyzed corpus of compounds, conclusions can be drawn that most of the compounds are almost (70\%) nouns, $8 \%$ are verb compounds, and $6 \%$ are special noun compounds.

\section{MORPHOLOGICAL PRODUCTIVITY OF NOUN COMPOUNDS}

The results show that out of 3574 compounds in the corpus, there are 2517 noun compounds (the list is available upon request) and they represent $70 \%$ of the $100 \%$ compounds in the corpus. The identification of noun compounds is based on the following patterns of noun compounding formation:

- Noun + noun

- Verb + noun

- Adjective + noun

- Adverb + noun

The identified 23 noun compounds that appear only once in the corpus are the following:

1. City-state

2. Ad agency

3. Attestation clause

4. Bankruptcy law

5. Bench trial

6. Company law

7. Copywriter

8. Criminal libel

9. Current account

10. Dead house

11. Deadlock

12. Death blow

13. Death toll

14. Jumble sale 
15. Personal ad

16. Offside

17. Senior statesman

18. Sleep-walker

19. Stool pigeon

20. Tax allowance

21. Title deeds

22. Title transferee

23. Writer-editor

After determining the exact number of the noun compounds in the corpus, and after identifying the noun compounds that appear only once in the corpus, the measurement of the morphological productivity of the nouns is followed. Findings show that there were twenty-three words (the list is available upon request) of the type hapax legomenon (n1) and 2517 tokens (N) which are the total number of this type of compounds in the analyzed corpus. Correspondingly, according to the formula $\mathrm{P}=\mathrm{n} 1 / \mathrm{N}$, the following results are obtained:P $=23 / 2517=$ 0.009137863. The identified twenty-three words of the type hapax legomenon in the analyzed corpus are noun compounds that are composed of two roots / words where the first word is a noun, verb, adjective, or adverb, and the second word is always a noun. By joining them, we get a noun compound.

\section{MORPHOLOGICAL PRODUCTIVITY OF SPECIAL NOUN COMPOUNDS}

Results show that out of 3574 compound words in the corpus, there are two hundred and twelve special noun compounds (the list is available upon request) and they represent $6 \%$ out of the $100 \%$ compounds in the corpus. The identification of the special noun compounds was done based on the following pattern of special noun compounds formation: Verb + adverb $=$ noun compound.

The identified 4 special noun compounds that appear only once in the corpus are the following:

\section{Bailout}

2. Standstill

3. Stowaway

4. Write-up 
After determining the exact number of the special nouns in the corpus and after identifying the special noun compounds that appear only once in the corpus, the morphological productivity was measured. Results showed that there were four words (the list is available upon request) of the type hapax legomenon (n1) and two hundred and twelve tokens (N) which are the total number of this type of compounds in the analyzed corpus. Correspond, according to the formula $\mathrm{P}=\mathrm{n} 1 / \mathrm{N}$, these results were obtained:

$$
P=4 / 212=0.018867925
$$

\section{MORPHOLOGICAL PRODUCTIVITY OF VERB COMPOUNDS}

Results show that out of 3574 compound words in the corpus, there are 293 verb compounds (the list is available upon request) and represent $8 \%$ of the $100 \%$ compounds in the corpus. The identification of the verb compounds is based on the following patterns of verb compounds: noun+ verb, verb+ verb, adjective + verb, adverb + verb.

The identified 8 verb compounds that appear only once in the corpus are the following:

1. fast-forward

2. downshift

3. shortchange

4. house-sit

5. sleep-walk

6. overrule

7. invigorate

8. underestimate

After determining the exact number of the verb compounds in the corpus and after identifying the verb compounds that appear only once in the corpus, the measurement of the morphological productivity of the verb compounds was done. Findings showed that there were eight words (the list is available upon request) of the type hapax legomenon (n1) and 293 tokens (N) which are the total number of this type of compounds in the analyzed corpus. Correspondingly, according to the formula $\mathrm{P}=\mathrm{n} 1 / \mathrm{N}$, the following results were obtained:

$$
\mathrm{P}=8 / 293=0.027303754
$$




\section{CONCLUSION}

Generally speaking, from this analysis it can be concluded that the most productive compounds are verb compounds with morphological productivity of 0.027303754 and special noun compounds (0.018867925). The compounds that were the least productive in the analyzed corpus are the nominal compounds with morphological productivity of 0.009137863 . Such results are not surprising at all, since it is expected that the nouns are expected to be the most commonly used words in the corpus of law. Bearing in mind that spoken words often result in low productivity, and rarely represented words lead to high morphological productivity, this research confirms that such a statement is accurate and logical, and from the findings there are reliable results.

This analysis shows that compounding is really productive, because in all three groups there is a significant fund of words that only appear once in the corpus. The detected words of the type hapax legomenon are not exactly neologisms, since the research was conducted among students and their knowledge of English did not lead to the formation or creation of new, non-existent words, but the words used, such as the hapax legomenon, or at least they could be, completely new to some of the participants involved in the study. Neologisms surely would have appeared if the research was conducted on the basis of comparing a written discourse of different time periods. Also, words of the type hapax legomenon would be neologisms if the participants in the research were authors or professionals in English for specific purposes in the field of law, so that nonexistent words would be formed based on their competencies and skills in English and their field of research. 


\section{REFERENCES}

- Baayen, R., H., Lieber, R. (1991). Productivity and English derivation: a corpus-based study. In "Linguistics", 29, pp. 801-843.

- Baayen, R., H. (1992). Quantitative aspects of morphological productivity. Yearbook of Morphology: Kluwer Academic Publishers, pp.109-149.

- Baayen, H. (2001). Word frequency distributions. Kluwer Academic Publishers: Dordrecht.

- Baayen, R., H. (1994a). Derivational productivity and text typology. In: ”Journal of Quantitative Linguistics" 1, 16-34.

- Baayen, R., H., Renouf, A. (1996). Chronicling The Times: Productive lexical innovations in an English newspaper. In: "Language" 72, 69-96.

- Baayen, R., H., Neijt, A. (1997). Productivity in context: a case study of a Dutch suffix. In: "Linguistics", 35: 565-587.

- Bauer, L. (1973). English word-formation. Cambridge: Cambridge University Press, London, UK.

- Bauer, L. (1983). English Word-Formation. Cambridge: Cambridge University Press.

- Bauer, L. (1998). When is a sequence of two nouns a compound in English? In: "English Language and Linguistics", 2, 65-86.

- Bauer, L. (2000a). Word. In: Geert Booij, Christian Lehmann and Joachim Mugdan (eds.). Morphology. An International Handbook on Inflection and Word-Formation, Volume 1, 247257. Berlin/New York: de Gruyter.

- Bauer, L. (2000b). Compounding. In: Geert Booij, Christian Lehmann and Joachim

- Mugdan (eds.). Morphology. An International Handbook on Inflection and Word-

- Formation, Volume 1, 695-707. Berlin/New York: de Gruyter.

- Bauer, L. (2001). Morphological productivity. Cambridge: Cambridge University Press.

- Campbell, L., Kaufman, T., Smith-Stark, C. (1986). Meso-America as Linguistic Area. In: "Language", 62: 3, pp. 530-570.

- Corbin, D. (1987). Morphologie dérivationelle et structuration du lexique. Tübingen: Max Niemeyer.

- Fernández-Domínguez, J., A. Díaz-Negrillo and P. Štekauer. (2007). How is low morphological productivity measured? In "Atlantis” 29, pp. 29-54.

- Fernández-Domínguez, J. (2008). Productivity measurement of English compounding based on a corpus of the nominal type. University of Jaén: Unpublished PhD dissertation.

- Fernández-Domínguez, J. (2009). Productivity in word-formation. An approach to $N+N$ compounding. Bern: Peter Lang.

- Fernández-Domínguez, J. (2010). Productivity vs. Lexicalization: Frequency -based Hypothesis on word formation. Poznan Studies in Contemporary Linguistics, Volume 46, Issue 2, retrieved 3.4.2015, from https://www.academia.edu/4782195/Productivity_vs._lexicalization_Frequencybased_hypotheses_on_word-formation.

- Fernández-Domínguez, J. (2013). Morphological productivity measurement: exploring qualitative versus quantitative approaches. In: "English Studies", 94(4), pp. 422-447. 
- Finegan, E. (2007). Language: Its Structure and Use. Thomson Wadsworth, 5th edition.

- Plag, I. (1999). Morphological Productivity. Structural Constraints in English Derivation. Berlin/New York: Mouton de Gruyter.

- Plag, I., Dalton-Puffer, C., Baayen, H. (1999). Productivity and register. In: ”English Language and Linguistics" 3, pp. 209-228.

- Plag, I. (2003). Word - Formation in English. Cambridge: Cambridge University Press.

- Plag, I. (2004). Syntactic category information and the semantics of derivational morphological rules. Folia Linguistica 38 (3-4), pp.193- 225.

- Sabri, F., M. (2003). Word-Formation Analysis: The Productivity of Compounding in English Short Stories. Retrieved on 09. 03.2015, from https://www.academia.edu/4271189/Word_Formation_Analysis_The_Productivity_of_Comp ounding_in_English_Short_Stories 